\title{
Research on Big Data Theory and Trend of Quality Management in Automobile Industry
}

\author{
Ke Chen ${ }^{1}$, Tianbo $\mathrm{Li}^{* 2}$, Xiaomin $\mathrm{Ma}^{3}$ \\ ${ }^{1}$ CATARC Huacheng Certification (Tianjin) Co., Ltd. China Automotive Technology and Research Center Co., Ltd. Tianjin, China \\ ${ }^{2}$ CATARC Huacheng Certification (Tianjin) Co., Ltd. China Automotive Technology and Research Center Co., Ltd. Tianjin, China \\ ${ }^{3}$ College of Management and Economic Tianjin University Tianjin, China
}

\begin{abstract}
As a typical manufacturing industry, the automobile industry has high requirements for quality management. Today, with the rapid development of information technology, it is important to consider the characteristics of quality management in the industry and the whole life cycle of automobile products. Based on this perspective, an evaluation index system of quality management data and a big data platform of quality management for the automobile industry were established. This research has guiding significance for governments to serve the development of the automobile industry and for enterprises to improve their quality capability.
\end{abstract}

\section{Background Introduction}

\subsection{Automobile Industry}

After the reform and opening-up, China's automobile industry has developed rapidly and has become the world's largest automobile producer and new car consumer market. The automobile industry has also become one of China's pillar industries. In 2019, the sales of new cars in China exceeded 25 million and the car parc reached 260 million. At the same time, quality problems of automobiles have begun to appear. Since 2004, recalling has taken place each year, and the number of recalling reached a record high of 20.048 million in 2017. The severe recalling situation of the industry reflects the supervision intensity of governments and consumers' higher pursuit for quality automobile products.

\subsection{Big Data Technology}

Big data is an information asset created in the information age, which has the characteristics of volume, variety, velocity and value [1]. Influenced by information technology, big data has been used in the entire life cycle like industrial $\mathrm{R} \& \mathrm{D}$ and design, production and supply chain management as well as operation and maintenance and service. Influenced by modern science and technology, the complexity and dynamics of the production process have appeared and the big data generated in the entire life cycle can no longer be managed and maintained by traditional information technology.

Opinions of the State Council on Strengthening the Building of the Quality Certification System and Promoting Comprehensive Quality Management (No. 3
[2018] of the State Council) pointed out: "Transform the traditional certification model with the Internet and big data and other new technologies and promote the comprehensive upgrading of quality management of enterprises by upgrading the certification of quality management systems. "In 2020, the last year of the 13th Five-Year Plan, Ministry of Industry and Information Technology issued the Guidance on the development of industrial big data, which presents clear requirements for the digital transformation of industry and quality economic development. The full coverage of $5 \mathrm{G}$ signals in the National Intelligent Internet of Things Application (North) Demonstration Zone has expanded data connectivity and provided convenience for data collection. Big data provides strong support for the development of manufacturing, financial industry, the internet industry and agriculture. Leading Internet enterprises like Alibaba, Baidu and Tencent are actively expanding their businesses with big data technology.

To sum up, we found that both countries and enterprises attach great importance to the application of data. China's automobile industry is no exception. A massive amount of data has been accumulated, but most of them are applied at the technology level and haven't combined well with quality management. Application of big data in the whole life cycle from a higher level has not been explored.

\section{Literature Review}

Automotive big data cover links of product design, manufacturing, sales, and application and connects enterprises, industrial and ecological chains and industry management. In recent years, the researches on automobile big data are often targeted at applications in

"litianbo@catarc.ac.cn 
one single aspect. Andre Luckow (2015) [2] investigated the deployment and application of Hadoop in automobile industry. Zhu (2016) [3] explored the formation mechanism of data integration value in automobile industry. Jiang (2017) [4] provided data support for the investigation of the product quality defect and consumption prediction by using big data technology. Liu (2017) [5] forecasted automobile prospective technology based on big data. Tian (2019) [6] analyzed the multisource quality safety data information and designed a vehicle defect risk assessment system which provides data and technical support for the warning of rapid vehicle defect risk. He (2019) [7] explored the impact of government incentive policies on automotive manufacturers under the background of big data. Song (2019) [8] provided support for the recall management of defective automobile products by using big data technology. Petrillo, A. (2020) [9] investigated the automobile system under the indicators of End-Of-Life and Remaining Useful Life. Lv (2020) [10] designed an automobile marketing system with application advantages according to the strength of big data technology. Ge et al. (2020) [11] analyzed the key technologies of automobile big data from many aspects and analyzed their development.

In summary, the application of big data in the whole life cycle of automotive quality management was not researched in depth. This paper aims to release the valuable information contained in automobile big data through data acquisition, transmission, storage, mining, and visualization so as to analyze the status quo of the quality of the industry and master the latest industrial trends; the paper provides methods for enterprises to make annual summaries of quality management to meet the goal of making a comprehensive analysis and benchmarking, optimizing the quality management capability of the enterprises and creating a benchmark of quality management.

\section{Big Data of Quality Management}

In 2018, CNCA established the public service platform "certification e-cloud", a national information certification and accreditation platform. It mainly includes the basic data of quality certification, namely the information related to product and system certification, but it does not include data related to quality management and the specific data of any certain industry. So the platform has certain limitations for analyzing the quality big data of automobile industry and leading the industry to achieve comprehensive quality management. In addition, in 2020, under the guidance of CNCA, China Automotive Technology and Research Center Co., Ltd. and other automobile enterprises established a data service platform of quality certification for China's automobile industry. A series of work such as data index planning and designing, data acquisition and analysis, platform architecture and system development, operation and maintenance of database and websites, industry service, and information sharing will be carried out.

\subsection{Establish an index system of quality big data}

Automobile manufacturing industry has the characteristics of a long industrial chain and a long life cycle. It takes 34 years for a new automobile to hit the market from $R \& D$ and there are many quality-control sections in the whole process, leading to the huge system, discrete data and low data value density of the enterprises' quality management. According to the characteristics of automobile industry, the index system of quality big data of automobile industry was established proceeding from the entire process of the market access of automobile products. The system has five first-level indicators and more than fifty second-level indicators after being expanded and refined.

\subsubsection{R\&D Quality Management}

Automobile enterprises have relatively complete quality management processes, such as ISO9001 and IATF16949, but in practical operation, product quality control is only conducted in the manufacturing process. Enterprises should be fully aware that implementing quality management in the design and development stage can ensure the process is always controllable. By doing so, enterprises can better understand customers' needs, thus improving the sales of products. Related secondary indicators include the achievement rate of design objectives and the on-time completion rate of milestone nodes.

\subsubsection{Procurement Quality Management}

Procurement is the foundation for the production and business activities of enterprises, thus it is vital for enterprises. The quality of products depends largely on the quality of purchased raw materials and components. When the quality of procurement is guaranteed, the qualified rate of products and production efficiency be improved; the cost of enterprises can be controlled; the core competitiveness of enterprises can be enhanced. Secondlevel indicators include the proportion of suppliers passing IATF16949 certification and completion rate for production part approval process.

\subsubsection{Production Quality Management}

In 2019, a total of 6,529,700 vehicles were recalled in 223 times of car recalling, of which 166 times or $74 \%$ of the recalling were for manufacturing reasons. Production quality determines whether products are qualified and is also an important factor affecting the long-term development of enterprises. The second-level indicators contained in the management of production quality include overall equipment effectiveness (OEE), first-pass yield, and achievement rate of quality goals.

\subsubsection{Quality of physical products}

Even the well-controlled quality of components and strict production process can't completely guarantee the quality of physical products. Unqualified products detected in the 
factory and those found by the customers after sales are products with poor quality, reflecting the results of the previous quality control process. The second-level indicators include incident per thousand vehicles (IPTV) in three months after sales, cost claim rate for a single unit and PPM of supplied components.

\subsubsection{Quality certification}

There are some limitations in the conformity evaluation of the tripartite certification of quality management in automobile industry. Enterprises have high demands for multi-dimensional evaluation of their quality management. It is beneficial for enterprises to improve their quality management if they know their position in the industry. Second-level indicators include the certification of ISO9001 and IATF16949 quality management systems, achievement rate of quality targets and closure rate of internal audits.

\subsection{The establishment of database and big data service platform}

Quality capability enables enterprises to create higher and more sustainable quality performance and it is also the essential factor and core of quality competitiveness. Analyzing and comparing the quality capability of different enterprises in automobile industry is the only way to transform China from a manufacturer of quantity to one of quality.

Based on the indicators determined in the previous chapter, the data indicators are collected in the enterprises and the calculation formula of indicators and the time cycle are designed.

The evaluation system can be divided into two parts (Table1): result quality (quality certification and market feedback) and process quality (self-reporting of enterprises and on-site audit). The quality capability evaluation model of automobile enterprises is constructed and the database covering domestic mainstream automobile brands is established. The service platform website of data information is developed.

Table1. evaluation method of quality capability

\begin{tabular}{|c|c|c|c|}
\hline \multirow{3}{*}{$\begin{array}{l}\text { Result } \\
\text { capability } \\
\text { of quality } \\
(40 \%)\end{array}$} & \multirow{2}{*}{$\begin{array}{l}\text { Quality } \\
\text { certification } \\
\text { (base mark) }\end{array}$} & System certification & Weight $10 \%-20 \%$ \\
\hline & & Product certification & Weight $10 \%-15 \%$ \\
\hline & Market feedback & Product recalling & Weight $5 \%-10 \%$ \\
\hline \multirow{4}{*}{$\begin{array}{c}\text { Process } \\
\text { capability } \\
\text { of quality } \\
(60 \%)\end{array}$} & \multirow{3}{*}{$\begin{array}{l}\text { Self-reporting of } \\
\text { enterprises } \\
\text { (mark according } \\
\text { to industry } \\
\text { practice) }\end{array}$} & R\&D quality Data & Weight $20 \%$ \\
\hline & & $\begin{array}{l}\text { Manufacturing } \\
\text { quality data }\end{array}$ & Weight $20 \%$ \\
\hline & & $\begin{array}{l}\text { After-sales quality } \\
\text { data }\end{array}$ & Weight $20 \%$ \\
\hline & On-site & On-site audit & $\begin{array}{l}\text { Deduct marks for } \\
\text { unqualified items }\end{array}$ \\
\hline
\end{tabular}

Then mark the indicators and evaluate quality capability of enterprises through various methods like synthetical index method and fuzzy comprehensive evaluation method. The evaluation results can be used for industry analysis. They can also provide technical support for manufacturing enterprises in the same industry and provide ways for enterprises to find their advantages and disadvantages.

\subsection{Big data analysis and evaluation method}

\subsubsection{Establish a quality management early warning system}

Firstly, the key processes and factors of quality management were analyzed and then major problems and risks were investigated and finally the early warning index system and thresholds were determined. Univariate and multivariate models are used to analyze the early warning content. Separate and multi-index early warning systems have been established for important indicators. The early warning is divided into three levels according to the index deviation degree. Monthly, quarterly and annual early warnings are adopted according to the content so as to comprehensively monitor the quality capability of the industry.

According to the data of the first time qualified rate of the complete vehicle of an enterprise in recent three years, the following data are obtained, as shown in Figure 1 and Table2. From the figure we can find that qualified rate shows seasonal fluctuation.

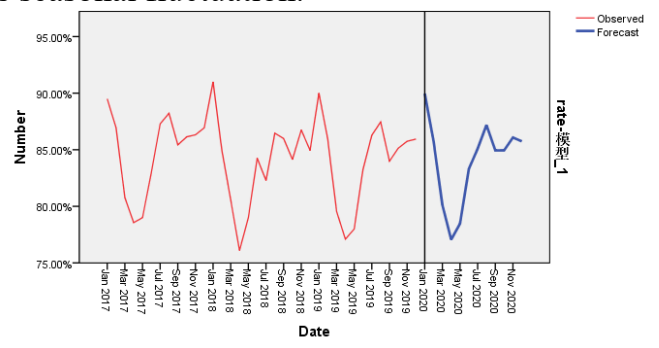

Fig 1. The prediction of first time qualified rate of the complete vehicle

Table2. predicted value of first time qualified rate of the

\begin{tabular}{|l|l|l|l|l|l|l|}
\hline complete vehicle (2020) \\
\hline $\begin{array}{l}\text { Time } \\
\begin{array}{l}\text { Predicted } \\
\text { value }\end{array}\end{array} 82020.10 \%$ & $87.19 \%$ & $84.94 \%$ & $84.95 \%$ & $86.08 \%$ & $85.75 \%$ \\
\hline
\end{tabular}

Other indicators will be added in the construction of big data platform in the future. By doing so, we can provide enterprises early warning model in advance based on predicted value and comprehensive early warning model. According to corresponding index evaluation methods, enterprises can make adjustments in advance, thus improving qualified rate.

\subsubsection{Predict the quality trend with SVM}

Support Vector Machines (SVM) theory is based on statistical learning. The method can be used for data analysis, pattern recognition and classification and regression analysis. It has obvious advantages in recognizing nonlinear multi-dimensional model with few samples. In recent decades, SVM has been widely used in many fields for its excellent classification capability and it is still one of the most popular research topics in machine learning.

In the quality management big data of the automotive industry, we can use effective index samples of enterprises to compare various parameters of quality management system based on SVM. And finally, a classification hyperplane for the whole industry can be found to distinguish competitive enterprises and ordinary ones, thus 
realizing make horizontal and vertical comparison of the quality and predict the quality trend of the industry.

\section{Conclusion}

With the increasingly stringent requirements of government departments on industry supervision, the data quality and processing capabilities of the automobile industry continue to improve. It is important to establish an evaluation strategy, criteria, and analysis method of quality data by considering the characteristics of quality management in the automobile industry and the whole life cycle of automobile products from multiple dimensions. A structured data model for the quality capability of automobile industry can be established by fully tapping the potential of data. And then a quality management data platform for regulation and certification organizations and automobile enterprises can be established through big data analysis. By doing so, the quality trend of the industry and quality capability of enterprises can be predicted. This research is of great importance for automobile industry and regulation of government departments. It will boost the quality management of the industry and facilitate its information service business.

\section{References}

1. V. Mayer-Schönberger, "Big Data: A Revolution That Will Transform How We Live, Work, and Think," Hodder, 2013, pp.69-91.

2. A. Luckow, K. Kennedy, and F. Manhardt, "Automotive big data: Applications, workloads and infrastructures," 2015 IEEE Internationl Conference on Big Data (Big Data), 2015, pp. 1201-1210.

3. Z. Xianglei, Z. Shuai, and Z. Lu, "Research on Data Integration of Automobile Industry Chain Driven by Big Data," Research on Automobile Industry, pp.4-11, Jan. 2016.

4. J. Zhaocai, S. Ning, and S. Li, "Preliminary Study on the Application method of Big data Analysis in the Risk Assessment of Product Quality Information," Standards Science, pp. 182-186, Dec 2017.

5. L. Guiru, M. Lingxiang, W. Lulin, and S. Zou, "Automotive prospective technology mining method based on big data content analysis," 2017 2nd IEEE International Conference on Cloud Computing and Big Data Analysis, 2017, pp. 171-174.

6. J. Tian, N. Sun, F. Fei, L. Song, S. Xu, "Design of Vehicle Defect Risk Assessment System based on Multi-source Information Fusion,” 2019 2nd International Conference on Safety Produce Informatization, 2019, pp. 546-551.

7. H. Xiaoyan, "Research on the evolution mechanism of the electric vehicle market driven by big data," Concurrency and Computation: Practice and Experience, 2020.

8. L. Song, N, Sun, Y. Yao, W. Zhang, and L. Chi, "Application of Data Mining Technology in the Recall of Defective Automobile Products in China-A
Typical Case of the Construction of Digital China," 2019 2nd International Conference on Safety Produce Informatization, 2019, pp. 541-545.

9. A. Petrillo, A. Picariello, S. Santini, B. Scarciello, and G. Sperlí, "Model-based vehicular prognostics framework using Big Data architecture," Computers in Industry, vol. 115, pp.103-177, 2020.

10. S. Lv, "Design of the automobile marketing system based on the big data," 2020 International Conference on Big Data Analytics for Cyber-Physical System in Smart City, 2020, pp. 1713-1719.

11. G. Yuming, H. Qingwen, W. Miaqiong, Z. Lingqiu, and L. Lu, "Application Model and Challenge Analysis of Automotive Big Data," Computer Science, vol. 47(06), pp.59-65, 2020. 